\title{
Planetary Multi-Personal Actualization: Potential Being-Net Formation in the Global Brain
}

\author{
Cadell Last ${ }^{1}$ \\ ${ }^{1}$ The Global Brain Institute, Center Leo Apostel, Vrije Universiteit Brussel, Pleinlaan 2, B-1050 \\ Brussels, Belgium \\ E-Mails: cadell.last@gmail.com
}

Accepted: March 3, 2015

There are two emerging trends that will most powerfully transform human society during the first half of the century: 1) increasing intelligence of the emerging planetary network of people, computers, and information technology (1), and 2) increasing interconnection of human biology with information technology (2). In this paper, I explore the potential of these two trends by combining global brain theory and transhuman theory, within a humanistic psychology framework. According to global brain theory, the first trend of increasing planetary connection will likely transform human organizational capabilities, allowing us to create distributed collective intelligence systems to solve global problems related to resource scarcity, international conflict, and ecological instability (3). According to transhuman theory, the second trend of increasing interconnection of human biology with information technology will likely transform human nature enabling us to extend our senses, enhance our biology, increase our ability to acquire knowledge, and radically transform the way we interconnect with other humans on a planetary scale (i.e. trans- or super-humanity) (4). From this theoretical exploration, we are left with the futuristic vision of a post-scarcity, post-conflict, self-organized super-human civilization, where humans are fully in control their own life history, capable of enhancing their own biologically inherited capacities with technology, and eventually able to directly interconnect mind-tomind (5).

However, the question remains open regarding what a globally interconnected, technologically enhanced, and individually liberated super-human species would do, often inspiring metaphors of "singularity" (6). In order to better explore this future possibility space, I utilize and update the psychological concept of the "hierarchy of needs" (7), individuals will satisfy the following needs in a generalized hierarchy: physiology, safety, love/belonging, esteem, and self-actualization, with selfactualization being seen as an open process of actualizing latent creative potentialities (8). More 
recent conceptualizations of the hierarchy of needs further explore the characteristics of selfactualization potentialities (9), but also include a level beyond self-actualization: self-transcendence (or: selfless actualization) where pure being and bliss take full form (10). This conception accounts for many ancient philosophical, spiritual, and intellectual traditions that have recognized the importance of "ego-transcending" states of being (11). However, this extension does not go far enough considering transhuman theory and evidence (12), and therefore I attempt to further extend our conceptualization of the hierarchy of needs with an explicit "multi-personal" dimension, i.e. the ability of multiple human minds to interconnect towards self-actualization/transcendence.

Therefore, I conclude this paper by exploring the potential for a multi-personal hierarchy of needs, where a post-scarcity, post-conflict super-human species develops towards planetary self-actualization, potentially culminating with the formation of a "Being-Net" (13) (historically referred to as a "Noosphere" (14), "Super-Being" (15), "Gaiafield" (16), "Global Brain Mindplex" (17), "World-Wide Mind" (18), "Brain-Net" (19)). In my conception, the Being-Net would be the free aggregation of all self-actualization human minds in planetary interconnection.

\section{References and Notes}

1. Glenn, J.C., Gordon, T.J., \& Florescu, E. 2014. State of the future 2013-14. The Millennium Project.

2. Kurzweil, R. 2005. The Singularity Is Near: When Humans Transcend Biology. Penguin.

3. Heylighen, F. 2015. Return to Eden? Promises and Perils on the Road to Global Superintelligence. In: Goertzel, B. \& Goertzel, T. (eds.), The End of the Beginning: Life, Society and Economy on the Brink of the Singularity. Humanity+ Press. Retrieved from: http://pespmc1.vub.ac.be/Papers/BrinkofSingularity.pdf

4. More, M. \& Vita-More, N. (eds.). 2013. The Transhumanist Reader: Classical and Contemporary Essays on Science, Technology, and Philosophy of the Human Future. WileyBlackwell.

5. Kaku, M. 2014. The Future of Mind: Scientific Quest to Understand, Enhance, and Empower the Mind. Doubleday.

6. Vinge, V. 1993. The Coming Technological Singularity. Whole Earth Review, 11-22.

7. Maslow, A. 1943. A Theory of Human Motivation. Psychological Review, 50: 370-396.

8. Maslow, A. 1971. The Farther Reaches of Human Nature. New York: Penguin.

9. Heylighen, F. 1992. A Cognitive-Systemic Reconstruction of Maslow's Theory of Motivation. Behavioral Science, 37: 39-58.

10. Koltko-Rivera, M.E. 2006. Rediscovering the Later Version of Maslow's Hierarchy of Needs: Self-Transcendence and Opportunities for Theory, Research, and Unification. In: Review of General Psychology, 10: 302-317.

11. Das. A.K. 1989. Beyond self-actualization. International Journal of the Advancement of Counselling, 12: 13-27.

12. Nicolelis, M. 2011. Beyond Boundaries: The New Neuroscience of Connecting Brains with Machines - and How It Will Change Our Lives. Macmillan.

13. Last, C. 2015. Big Historical Foundations for Deep Future Speculations. In Press: Foundations of Science. 
14. Teilhard de Chardin, P. 1955. The Phenomenon of Man. London: Collins.

15. Turchin, V. 1977. The Phenomenon of Science. New York: Columbia University Press.

16. Russell, P. 1983. The Global Brain Awakens: Our Next Evolutionary Leap. Palo Alto: Global Brain Inc.

17. Goertzel, B. 2003. The Potential Emergence of Multiple Levels of Focused Consciousness in Communities of AI's and Humans. Novamente LLC.

18. Chorost, M. 2011. World Wide Mind: The Coming Integration of Humanity. Simon and Schuster.

19. Nicolelis, M. 2011. Beyond Boundaries: The New Neuroscience of Connecting Brains with Machines - and How It Will Change Our Lives. Macmillan.

(C) 2015 by the authors; licensee MDPI and ISIS. This abstract is distributed under the terms and conditions of the Creative Commons Attribution license. 